\title{
VIAGENS E PASSEIOS FAMILIARES E ESCOLARES REGISTRADOS EM CADERNOS DE ALUNOS (1957-2015)
}

ELIANE PERES

Universidade Federal de Pelotas

RESUMO Este artigo aborda registros de viagens e de passeios localizados em cadernos de alunos de um acervo específico. Os cadernos correspondem ao que hoje se denomina de anos iniciais do Ensino Fundamental e cobrem o período dos anos de 1950 até os dias atuais. Assim, procura-se analisar, sob a ótica infantil, os registros tanto de viagens - entendidas como deslocamentos de mais longa distância, ou seja, intermunicipais e interestaduais -, quanto de passeios - entendidos como deslocamentos na própria cidade ou na zona de localização da casa e/ou da escola. São apresentados, primeiramente, textos que permitem problematizar as experiências familiares das crianças - portanto pessoais e privadas - com passeios ou viagens. De tal modo, foi possivel apreender como elas se referem a essas atividades, feitas, em geral, durante as férias, às redes de relações familiares ampliadas que vivenciam e a alguns acontecimentos que consideram relevantes de serem registrados, especialmente no que tange às brincadeiras, ao estudo e a pequenas tarefas executadas no âmbito doméstico. Na sequência, são destacados textos das crianças que indicam viagens e passeios realizados na esfera escolar. Uma das conclusões possíveis é a de que a escola promove, via de regra, passeios culturais (cinema, teatro, biblioteca) e "passeios-informação", a fim de trabalhar determinados conteúdos curriculares.

Palavras-chave: Viagens e passeios. Cadernos escolares. Textos infantis.

\section{ABSTRACT SCHOOL AND FAMILY OUTINGS AND TRIPS REGISTERED IN STUDENTS' NOTEBOOKS (1957-2015)}

This article analyzes records of trips and outings found in students' notebooks from a specific archive. Those are notebooks from the early years of basic education and cover the historical period from the 1950's to today. Thus, we seek to investigate, under the children's perspectives, the record of trips - understood here as a long-dis- 
tance displacement, such as between different cities or states - and of outings - understood here as displacement inside the city itself or around the location of the student's house or school. Firstly, we present texts that contextualize children's family experiences - therefore, personal and private - within trips or outings. This way, we could comprehend how they refer to these activities that are carried out, in general, during vacations, to the broad network of family relationships that they experience, and to some events that they consider relevant to be recorded, especially play time, study and small chores. Then, we highlight texts from children who indicate school trips and outings. One conclusion is that schools promote, as a rule, cultural outings (cinema, theater, library) and "information outings" in order to approach specific curricular contents.

Keywords: Trips and outings. School notebooks. Childrens texts.

\section{VIAJES Y PASEOS FAMILIARES Y ESCOLARES} REGISTRADOS EN CUADERNOS DE ALUMNOS (1957-215)

Este artículo aborda registros de viajes y paseos encontrados en cuadernos de alumnos de un acervo específico. Los cuadernos corresponden a lo que hoy se denomina primeros grados de la Escuela Primaria y cubren el período de los años 1950 hasta los días actuales. Así, se busca analizar, bajo la óptica infantil, tanto los registros de viajes - comprendidos como desplazamientos de más larga distancia, es decir, intermunicipales e interestaduales -, cuanto de paseos - comprendidos como desplazamientos en la propia ciudad o en la zona de ubicación de la casa y/o de la escuela. Son presentados, en primer lugar, textos que permiten la problematización de las experiencias familiares de los niños - por lo tanto personales y privadas - con paseos o viajes. De este modo, fue posible comprender cómo ellos se refieren a estas actividades más amplias, hechas, en general, a lo largo de las vacaciones, a las redes de relaciones familiares ampliadas que viven y a algunos eventos que consideran relevantes para su registro, especialmente en lo que se refiere a los juegos, al estudio y a pequeñas tareas ejecutadas en el ámbito doméstico. Luego son destacados textos de niños que indican viajes y paseos realizados en la esfera escolar. Una de las conclusiones posibles es la de que la escuela promueve, generalmente, paseos culturales (cine, teatro, biblioteca) y "paseos-información", con la intención de trabajar determinados contenidos curriculares.

Palabras clave: Viajes y paseos. Cuadernos escolares. Textos infantiles. 


\section{Introdução}

A literatura, em especial a infantil, tem prodigiosos exemplos da exploração do tema da redação sobre as férias. Dois deles, no entanto, são especialmente admiráveis, tanto pela qualidade literária do texto, quanto pela capacidade que as autoras demonstram em revelar, em uma narrativa crescente, os acontecimentos e os sentimentos dos protagonistas em relação à imposição de fazer uma redação escolar sobre as férias. O primeiro deles é Minhas férias, pula uma linha, parágrafo, da brasileira Christiane Gribel (1999), com ilustrações de Orlando Pedroso, publicado pela Editora Salamandra. Nessa narrativa, o narrador e personagem protagonista é um garoto de onze anos, Guilherme Pontes Pereira, aluno da 6 a série $B$, que, no primeiro dia de aula, precisa fazer uma redação de 30 linhas sobre as férias e, posteriormente, a análise sintática de uma das sentenças da redação. As agruras de Guilherme, antes, durante e depois da realização da tarefa são magistralmente narradas no texto. Ao final, achando que seria expulso da escola, em razão da atividade escolar, o garoto é enviado ao diretor que, após a conversa com ele, dá o veredito: “Guilherme eu fiquei muito impressionado com a história que você escreveu. Você precisa fazer mais redações". o narrador/protagonista então conclui:

\section{[...] Então ele me mandou de volta para a sala de aula. \\ Eu fiquei pensando muito nisso tudo porque no começo eu não estava entendendo nada. Mas depois descobri porque escolheram aquele cara para ser o Diretor. Ele é bem inteligente. Fazer mais redações era mesmo um castigo muito pior do que ser expulso da escola. (GRIBEL, 1999, p. 37) \\ O outro exemplo advindo da literatura é} Frida, da colombiana Yolanda Reyes (1999), com ilustrações de Olga Cuéllar e tradução para o português de Ruth Rocha (Editora FTD). Nesse caso, Santiago, o narrador/protagonis- ta, também um menino de 11 anos, é impelido a fazer uma composição sobre as férias, no primeiro dia de aula. Nela, ele relata como se enamorou, durante suas férias, da menina Frida, uma sueca neta de colombianos que passa uma temporada na casa dos avós na Colômbia. A descrição, feita por Santiago, sobre a beleza de Frida e sobre os dias que juntos passaram, é impecável. Em suas palavras, ela era lindíssima e o tempo que permaneceram juntos foram os melhores de toda a sua existência: "Nem sei como pude viver estes onze anos da minha vida sem ela. Não sei como fazer para viver de agora em diante", escreve Santiago, ao rememorar suas férias.

A bela e emocionante narrativa de Yolanda Reyes, assim começa:

De volta à escola. Outra vez, o primeiro dia de aula. Faltam três meses, vinte dias e cinco horas para as próximas férias. $O$ professor não preparou a aula. Parece que o novo curso o apanhou de surpresa. Para sair desse impasse, ele ordena, com a voz de sempre:

- Peguem seus cadernos e escrevam com esferográfica azul e com letra legivel uma composição sobre as férias. No mínimo uma página, de margem a margem, sem pular nenhuma linha. Cuidado com a ortografia e com a pontuação. Vocês têm quarenta e cinco minutos. Alguma pergunta?

Não há perguntas. E nem respostas. O que há é a mão que não obedece às ordens, porque está chegando das férias. É um caderno pautado de cem páginas que estreia hoje com o velho tema de todos os anos:

O QUE FIZ NAS MINHAS FÉRIAS? (REYES, 1999, p. 5-6)

Então, Santiago começa a escrever e o faz de forma comovente: o namoro com Frida, as românticas atividades de férias e a despedida de ambos tinham sido as experiências mais emocionantes e intensas da vida do menino de onze anos. Contudo, ao final do tempo estipulado pelo professor para a composição escolar, eis o desfecho assim narrado: 
[...] Levanto a cabeça e descubro os olhos do professor cravados nos meus.

- Vamos Santiago. Leia em voz alta o que escreveu, tão concentrado.

Eu então começo a ler com a voz de sempre a mesma composição de todos os anos:

'Nas minhas férias não fiz nada de especial.

Não fui a lugar nenhum, fiquei em casa, arrumei meu quarto, joguei futebol, li muitos livros, andei de bicicleta, etc., etc., etc...'

o professor me olha com um olhar longinquo, descrente e distraído. Será que ele também se apaixonou nessas últimas férias? (REYES, 1999, p. 29)

Embora se trate de ficção, notavelmente criada por Christiane Gribel e Yolanda Reyes, ambas as narrativas guardam aquilo que caracteriza, via de regra, um texto literário: a verossimilhança. Segundo Borges (2015, p. 53):

Verossimilhança seria uma possibilidade da verdade, algo, talvez, como uma mentira nãogrosseira, que não escandaliza uma verdade provável. Tal conceito é essencial no fazer literário porque abre espaço para todas as possibilidades simbólicas no tocante à história, à sociedade, aos seres humanos. Algo que se pretende verossímil está inevitavelmente atrelado ao entendimento das referências que norteiam a sua constituição.

Essa "verdade provável" está, por exemplo, nas ordens de ambos os mestres (professora, na narrativa de Gribel, e professor, na de Reys) para a execução da atividade escolar: observação do número de páginas, do número de linhas, das regras ortográficas, do tempo de duração, das formalidades do texto escolar, como margens, pontuação, parágrafo etc.; também está presente nos sentimentos experienciados pelos meninos antes, durante e depois da escrita do texto solicitado; nos resultados da avaliação dos mestres.

Assim, é inevitável, ao ler os registros de passeios e viagens feitos em cadernos escolares ${ }^{1}$ pelos alunos e alunas, objeto de estudo

1 Nos limites deste artigo não cabe a discussão sobre pesquisas com/em cadernos escolares. Remeto, assim, para alguns estudos nesse campo: Gvirtz (1999); que resultou neste texto, pensar em que medida, no cumprimento dessa tarefa escolar, em especial quando se referem às redações ${ }^{2}$ sobre as férias, as crianças inventaram, reinventaram, omitiram, copiaram etc. 0 exemplo a seguir, retirado de um caderno de literatura guardado no acervo pesquisado, de uma aluna de um 5 o ano, de uma escola privada, nos faz, no mínimo, refletir sobre isso:

Diário de viagem ${ }^{3}$

Dia 23 de Dezembro de 2012

Oi, diário, hoje vou para casa da minha avó, junto com minha irmã.

Estou arrumando minhas malas. Lá vai ter muita neve. É no Canada.

Estou louca para ver minha avó

Vou passar o natal com ela.

Eba!

Dia 24 de Dezembro de 2012

Oiii, diário!

Cheguei no Canadá, agora vou escalar montanhas com minha irmã.

Eu estava olhando os rios, e estavam quase todos congelados. Tomara que mamãe deixe a gente patinar no gelo.

Minha vó está me chamando para tomar chocolate quente com marshmallows. Humm!

Beijo! Tchau

Dia 25 de Dezembro de 2011[?]

Olá Diário, hoje é o natal! Tomara que eu ganhe muitos presentes

Eu acho que eu e minha irmã vamos ganhar um tablet e um Iphone coisa mais linda do mundo! E claro que eu vou te dar um presente. Uma caneta nova com uma ponta macia

Beijos tchau!

(C11, 2012, 5o ano, F, EPa, Pelotas, RS) ${ }^{4}$

Hébrard (2001); Chartier (2002; 2007); Viñao (2008); Mignot (2008); Peres (2008; 2012).

2 No primeiro texto literário aqui utilizado, a autora, Christiane Gribel, usa a denominação redação; no segundo, de Yolanda Reyes, a denominação é composição. Não vou entrar na discussão dos gêneros textuais e daquilo que hoje se denomina, na escola, de produção textual, pois há autores que, de forma competente, abordam isso (Cf. Marcuschi, 2002) e que, no caso deste artigo, não é o foco.

3 A escrita das crianças será preservada em todos os textos.

4 Os dados de identificação do caderno são os se- 
No conjunto dos textos coletados para este estudo, nesse caso indaga-se: trata-se de um texto que narra uma experiência vivida? Desejada? Inventada? Copiada? No confronto com os textos ficcionais, Minhas férias, pula uma linha, parágrafo e Frida, ler Diário de viagem, localizado em um caderno de 2012, serve, no mínimo, como um alerta no estudo da temática em pauta: passeios e viagens registrados por escrito pelas crianças em cadernos, como tarefa escolar, seja como demanda da tradicional redação "Minhas férias", seja como resultado de atividades pedagógicas, não refletem necessariamente aquilo que se passou ou aquilo que as crianças sentiram ou viveram de fato. Nesse caso, precisa-se tentar evitar uma visão ingênua e simplista das crianças e de suas produções textuais. Sabe-se que, na condição de alunos e alunas, como tão bem revelam as narrativas literárias citadas, as crianças encontram estratégias para resolver as tarefas escolares de acordo com os parâmetros da cultura escolar e docente.

Mesmo considerando isso, os dados coletados para este estudo permitem algumas considerações que são propostas neste artigo, em referência aos passeios e viagens registrados pelas crianças. Esses dados coletados e aqui problematizados, cujo exemplo reproduzido anteriormente (Diário de viagem) é atípico, mas reflexivo, advêm de mais de novecentos cadernos de crianças, guardados e preservados no acervo do grupo de pesquisa História da Alfabetização, Leitura, Escrita e dos Livros Escolares (HISALES), da Faculdade de Educação da Universidade Federal de Pelotas (RS). ${ }^{5}$

guintes (que aparecerão em todas as citações neste artigo): a letra $C$ ou $C O$ seguida de um número, que representa o código do caderno no acervo geral; na sequência está o ano civil, seguido da série/ano escolar, da letra $F$ ou $M$, em referência à Feminino ou a Masculino, e das letras EPa ou EPu, que significam, respectivamente, Escola Particular e Escola Pública; por último, a cidade e o Estado.

5 Atualmente, há no acervo 1280 cadernos de alunos. Desses, 974 correspondem ao que hoje se denomina
Atualmente, o acervo é composto de cadernos que cobrem o período dos anos de 1920 até os dias atuais. Para este estudo, fizemos uma coleta em todos eles, referente aos primeiros anos do que hoje conhecemos por primeira etapa do Ensino Fundamental (até o 5o ano), e os resultados são os seguintes: foram localizados textos sobre a temática de estudo em 76 cadernos e, em alguns deles, há mais de um registro, perfazendo 105 recorrências ao todo.

Nos cadernos dos anos de 1920, 1930 e 1940, que juntos somam seis, não há registros sobre a temática dos passeios, viagens, férias, excursões. É em um dos cadernos dos anos de 1950, três no total, que se encontra o primeiro texto sobre isso, especificamente no de 1957. Depois, na sequência das décadas, os anos de 1960 contabilizam 21 cadernos, há dois com registros sobre os assuntos; nos anos de 1970, são 13 cadernos, e não há recorrências das temáticas pesquisada; nos cadernos dos anos de 1980, um total de 37, foram localizados dois com registros sobre os temas; nos anos de 1990, de um total de 233 cadernos, 12 apresentam textos sobre as temáticas; nos cadernos dos anos 2000, de um total de 452, em 24 deles foram localizadas recorrências dos temas pesquisados; finalmente, nos cadernos dos anos de 2010 em diante, no total de 406, em 35 há reincidência das temáticas. ${ }^{6}$

No universo dos cadernos do acervo, há menos recorrências acerca de passeios e viagens do que se imaginava. Por isso mesmo, considera-se relevante tentar extrair deles aquilo que os alunos e as alunas conseguiram expressar sobre essas atividades, pessoais-familiares ou escolares, permitindo problematizar aspectos

de anos iniciais ou primeiro segmento do Ensino Fundamental (até 5o ano). Sobre as políticas de acervo e as pesquisas realizadas no referido grupo de pesquisa, ver especialmente Peres (2011); Peres e Ramil (2015a; 2015b).

6 Sou grata às bolsistas de Iniciação Científica pelo trabalho realizado: Tatiara Timm Herreira (CNPq), Júlia Victoria Casalinho (CNPq) e Indiara Gaia da Silva (FAPERGS). 
da vida cotidiana das crianças, o que fazem ou dizem que fazem, o que conseguem perceber e ver nessas situações e como registram isso, bem como em que medida a escola proporciona atividades dessa natureza para as crianças e quais são suas finalidades.

Outros dados são importantes destacar: desses 76 cadernos em que as recorrências foram localizadas, 41 são de meninas, 34 de meninos e em um deles não há essa identificação. Esse dado é importante, uma vez que as brincadeiras são um dos aspectos mais enfatizados pelas crianças, em seus registros escritos, quando se referem às atividades feitas em passeios e viagens, sendo, portanto, possivel discutir também algumas questões de gênero, embora parcialmente.

Desse total, destaca-se, ainda, que, nos 76 cadernos em que há registro escrito das temáticas em pauta, 30 são de alunos e alunas que frequentaram escolas particulares, 43 são de estudantes de escolas públicas (municipais, estaduais e um de escola federal) e, em três deles, não há identificação de escola. Há um certo equilíbrio, portanto, entre as esferas de ensino, particular e pública, sendo levemente superior a recorrência das escolas públicas. Contudo, é preciso enfatizar que no acervo geral há essa superioridade numérica de cadernos de escolas públicas. Nenhuma conclusão em relação ao vínculo entre passeios e viagens e escolas públicas e privadas é possivel ser feita, nesse momento com esses dados, pelo menos não quantitativamente, mas qualitativamente: o que fazem e registram crianças de escolas públicas e privadas? Teoricamente, elas representariam dois grupos sociais que se diferenciam em relação às condições de vida. Se isso se expressa ou não nos dados extraídos dos cadernos é um aspecto a considerar nas reflexões.

No conjunto dos 76 cadernos em que há registros, 73 foram usados em escolas de diferentes municípios do Rio Grande do Sul, em especial os da Região Sul do Estado, característica do acervo geral; dois foram de alunos que frequentaram escolas em outros Estados brasileiros (Paraná e Minas Gerais); e um de um aluno brasileiro que frequentou a escola em Lisboa, Portugal, no final dos anos de 1990. Assim, considera-se que os cadernos são representativos da realidade das escolas gaúchas, em especial de uma região do Estado. Quando os casos apresentados extrapolam esse contexto, são apenas exemplares para mostrar que determinadas atividades excedem os limites geográficos impostos pelas características predominantes nas fontes de pesquisa.

Por fim, ainda em relação às 105 recorrências presentes nos 76 cadernos, a maioria dos textos das crianças refere-se a passeios, entendidos como deslocamentos na própria cidade ou zona de localização da moradia e/ou escola, para visitas aos familiares, a casas de amigos ou a pontos turísticos, prédios, instituições, espaços públicos e privados, eventos culturais etc. Por outro lado, alguns textos referem-se à categoria viagens, entendidas como deslocamentos de mais longa distância (fora dos limites da cidade, do Estado, ou seja, principalmente intermunicipais e interestaduais).

Para apresentar esses dados, o presente artigo foi dividido em duas seções. Na primeira, a ênfase é dada aos textos que indicam viagens e passeios familiares, via de regra, sobre as férias; na segunda, são enfatizadas essas mesmas atividades feitas, contudo, no âmbito escolar, destacando seu caráter didático-pedagógico e cultural, e procurando apreender os sentidos que a escola dá aos passeios e às viagens.

\section{Viagens e passeios familiares registrados nos cadernos escolares}

Como já foi referido, serão considerados primeiramente os textos localizados nos cader- 
nos referentes às viagens e aos passeios familiares. Nesse caso, interessa analisar como os alunos e as alunas se reportam a essas atividades e que rede de relações e acontecimentos, na vida privada das crianças, é possivel apreender nesse tipo de registro, como também já se destacou.

Assim, no que tange aos registros de viagens de férias, que retratam situações familiares, os mais recorrentes são aqueles cujos destinos são as casas de parentes, em cidades próximas aos locais de moradia das crianças. No primeiro caso, que será reproduzido, o menino refere-se aos passeios de férias na casa dos amigos e de parentes e a uma viagem à cidade de Piratini.? 0 dado torna-se mais inte-

7 A cidade de Piratini é referenciada várias vezes nos textos coletados nos cadernos das crianças, tanto em registros de passeios e viagens familiares, quanto escolares. Isso se deve ao fato de que Piratini é uma "cidade histórica", que representa, de alguma forma, o "orgulho gaúcho", de um povo "diferenciado", que se rebelou contra o governo federal durante o Império. Ela foi a primeira capital Farroupilha, quando, em razão da chamada Revolução Farroupilha ou Guerra dos Farrapos (1835-1845), os liberais gaúchos, descontentes com a política do governo imperial, se insurgiram contra o Império e iniciaram um conflito armado contra o governo central, decretando a República Rio Grandense. Segundo o site oficial da Prefeitura Municipal de Piratini, “em 1835, estavam sendo concluídas as obras da Igreja Matriz quando a revolução chamou às lides bélicas os habitantes da localidade. Importantes acontecimentos se desenrolaram no município por ocasião da Revolução Farroupilha: a 8 de outubro, a Vila foi ocupada pelos farrapos e, a 12 de dezembro, chegou a Piratini o coronel Antônio de Souza Neto, nomeado para chefe da Legião de Guardas Nacionais da Comarca, sendo organizados os Corpos, em 4 companhias e que deram origem à famosa 'Brigada Liberal'. Piratini, dada sua posição estratégica e o calor com que seus habitantes receberam o movimento, foi escolhida para centro das operações, começando a ser, já no início, o verdadeiro abrigo da Revolução que se estenderia por dez anos. A 11 de setembro de 1836, após a memorável vitória de Souza Neto nos campos de Seival, é proclamada a República e, já a 5 de novembro, a Câmara Municipal adere ao novo regime. Sob a presidência de Vicente Lucas de Oliveira, declara-se a Província em 'Estado Livre, Constitucional e Independente', com a denominação de 'Estado Rio Grandense', podendo ligar-se por laços de federação àquelas províncias do Brasil que adotassem o mesmo sistema de governo". Disponivel em: <http://www. prefeiturapiratini.rs.gov.br/site/historia>. Acesso em: 15 fev. 2017. Atualmente, o municipio tem 19.841 habitantes e ocupa, no Sul do Rio Grande do Sul, uma área ressante na medida em que o contexto vem à tona. Trata-se de um caderno utilizado em uma instituição educativa situada na zona rural, ou seja, ao que hoje denominamos de escola do campo. ${ }^{8}$ Assim, como registrou o aluno, ele "tirou" cinco dias em Piratini ou, como diz também, "passeou na cidade", como se pode ler:

Nas ferias que já passaram eu aproveitei passiando em casa dos meus amigos e parentes tirei cinco dias em Piratini passiei bastante na cidade. (CO4, 1967, 5o ano, M, EPu, Piratini, RS)

Estudante de uma escola pública e moradora do campo nos anos de 1960, para essa criança passear na cidade ("tirar os dias") e na casa de amigos e parentes eram, provavelmente, atividades importantes de férias. Possivelmente, o difícil acesso à cidade e o alto custo disso fazia do deslocamento uma "viagem", talvez esporádica, por isso mesmo especial!

Como em outros exemplos que serão aqui problematizados, o registro da vida das crianças que vivem e/ou estudam no campo indica a coexistência das brincadeiras, do trabalho e do estudo. Não é possível, pelos dados disponíveis, dimensionar a proporção de cada uma dessas atividades em suas vidas. Mas seus textos deixam margens para a reflexão dessa condição: afirmam que passeiam e fazem pequenas viagens, mas igualmente registram que férias é um período de ajudar no trabatho de casa e, por vezes, de estudar. Tais constatações, que mereceriam estudos empíricos de maior envergadura, por serem indicadores importantes, podem ser problematizados na relação com outras pesquisas que apontam, por exemplo, que "a aprendizagem na escola é o trabalho social obrigatório, que se exige de

de 3.539,688 km2. Disponível em: <http://cidades.ibge. gov.br/painel/painel.php?codmun=431460>. Acesso em: 15 fev. 2017. Piratini é distante da capital gaúcha, Porto Alegre, aproximadamente $344 \mathrm{~km}$ e, de Pelotas, em torno de $100 \mathrm{~km}$.

8 Decreto no 7.352, de 4 de novembro de 2010. Dispõe sobre a política de educação do campo e o Programa Nacional de Educação na Reforma Agrária - PRONERA. 
todas as crianças, enquanto sua colaboração na empresa paterna e no trabalho doméstico tornou-se mais rara e mais escassa (ZEIHER, 2007, p. 53). Os textos coletados no presente estudo assinalam a existência da colaboração das crianças nas tarefas cotidianas da casa e a participação em atividades de pequenos trabalhos com os pais e familiares em geral, aparentemente não tão raras e escassas assim. 0 adequado a se indagar é: quais crianças fazem isso? Por que fazem? Sob que condições fazem? Os dados deste estudo estão longe de poder responder a essas questões, mas possibilitam fazê-las para que, talvez, outros pesquisadores e pesquisadoras possam seguir as trilhas desses indícios. ${ }^{9}$

No segundo exemplo, para além das marcas culturais e linguísticas da oralidade e do nível de escrita do aluno de 1á série, em processo de alfabetização, que chama a atenção, mas que não é um aspecto aqui analisado, também é possivel observar, mais uma vez, aquilo que é recorrente nos dados deste estudo: os relatos dos passeios e viagens feitos no âmbito doméstico revelam a rede de relações familiares na qual as crianças estão inseridas. Nesse caso, um menino que frequentou a 1a série, em 1985, deslocou-se, em férias, da cidade de Morro Redondo, ${ }^{10}$ seu local de moradia, para Sanga Funda"1 para visitar a casa dos tios

9 Ver, por exemplo, o estudo de Cecílio (2002) sobre o trabalho precoce e penoso das crianças e adolescentes, moradoras de zonas rurais.

10 Morro Redondo emancipou-se de Pelotas através de plebiscito realizado em 10 de abril de 1988. O município fica distante de Pelotas aproximadamente 43 $\mathrm{km}$. De tradição agrícola, “o município se estende por $244,7 \mathrm{~km}^{2}$ e contava com 6.231 habitantes no último censo. A densidade demográfica é de 25,5 habitantes por $\mathrm{km}^{2}$ no território do município". Disponível em: <http://www.cidade-brasil.com.br/municipio-morro -redondo.html>. Acesso em: 20 fev. 2017.

11 Não é possível precisar o lugar exato a que a criança se refere no texto, uma vez que há duas importantes comunidades na região com o nome de Sanga Funda. A primeira, um distrito do município de Canguçu, que faz divisa com Morro Redondo, portanto uma localidade da zona rural; a segunda, um importante bairro na cidade de Pelotas, bastante populoso que reúne trabalhadores e uma população pobre. Segundo Silva e primos, referidos no texto de forma bastante afetiva:

As férias

As férias passaram ligeiro e foram boas. Eu passei lá na Sanga Funda no primo.

Não queria que eu viesse embora, meu priminho chorava, chorava

Meu primo Patrique é o melhor primo que eu tenho eu ganhei um balão, meu tio querinha que nois jovaga no capin

Ta bem o meu tio daqui apouco pun estourou

A culpa é do tio. (C02, 1985, 1a série, M, EPu, Morro Redondo, RS)

Os deslocamentos para visitas aos familiares entre zonas urbanas e rurais ou entre municípios próximos são, assim, as viagens mais frequentes registradas, especialmente nos apontamentos sobre as férias. No caso a seguir, a menina, moradora da cidade de Pelotas, escreveu que visitou a madrinha (dinda) e a avó, respectivamente nos municípios de Morro Redondo e Cerrito,12 ambos próximos à cidade em que residia, Pelotas. Nesse caso há, no ca-

(2014, p. 4), "apesar do bairro se encontrar no perímetro urbano da cidade ele apresenta muitas características de zona rural [...], muitos dos moradores produzem seu sustento, com plantações e criações de animais. Porém, esta não é a principal fonte de renda dos moradores, pois nesse bairro encontram-se mais de vinte olarias (pequenas indústrias que fabricam tijolos e cerâmicas), absorvendo a maioria da mão-de -obra masculina do local e sendo a principal fonte de renda dessas famílias. O bairro ainda conta com um frigorífico de grande expressão regional, que também absorve parte da população economicamente ativa". Em qualquer um dos casos, contudo, o deslocamento do menino revela um pertencimento geográfico e social da família.

12 Cerrito é distante de Pelotas aproximadamente 58 $\mathrm{km}$. Os dados indicam que "o Município de Cerrito foi criado em 28 de dezembro de 1995, através da Lei no 10.656, tendo como município de origem Pedro Osório. Localizado no Extremo Sul do Estado do Rio Grande do Sul, possui uma área de $451,9 \mathrm{~km}^{2}$ e 6.738 habitantes. Possui a economia voltada ao setor agropecuário tendo como maior expressão a produção leiteira com criação de gado da raça Jersey [...]. Constituído por pequenas propriedades rurais e minifúndios, destacase a produção de milho, soja, pêssego arroz e a avicultura. Na zona urbana destacam-se as olarias, com grande produção de tijolos, que é comercializado em toda a Região Sul". Disponivel em: <http://www.cerrito.rs.gov.br/novo_site/index.php?nivel=1\&exibir=secoes\&ID=1>. Acesso em: 26 jan. 2017. 
derno, o registro do enunciado dado pela professora: "Escreva um pequeno texto (máximo 10 linhas) explicando o nome das brincadeiras que você mais brincou nas férias" (qualquer relação com a ficção não é mera coincidência!). A resposta à tarefa veio com as seguintes palavras:

Nas minhas férias fui no arroio
Fui na minha dinda no Morro Redondo
No me vô que mora no Cerrito
Lá eu fiquei brinquei de médica. Com a minha
prima minha priminha foi la na minha casa
Brinquei de bebê chorão quando eu disse cho-
rão ela deu um risadão
Foi muito legal até o fim das férias. (CO23, 2013,
40 ano, F, EPu, Pelotas, RS)

Tomar banho de arroio, brincar de médica e de boneca (bebê chorão), visitar o avô, a prima, a madrinha, fizeram as "férias legais" dessa menina que, possivelmente tinha, em 2013, quando do registro, por volta de nove anos de idade. É possivel especular, pelas brincadeiras e pelos lugares frequentados, pequenas cidades de fortes características agropecuárias e de significativa concentração populacional em áreas rurais, que se trata de uma infância que ainda dispõe de espaços abertos para brincar (arroios, campos) e que mantém vínculos familiares intergeracionais fortes. Assim, podese considerar que "brincadeiras de áreas rurais têm algumas características particulares: acontecem em amplos espaços em contato direto com a natureza, fundindo-se dos elementos do entorno que motivam esses repertórios lúdicos" (FRIEDMANN, 2012, p. 26).

Longe de romantizar essa infância, o destaque é feito aqui justamente no sentido da não homogeneização e universalização dessa etapa da vida. Afirmar, genericamente, que as crianças não brincam mais, que não se interessam por brincadeiras ao ar livre, que vivem "fechadas" e absortas com aparatos tecnológicos (computadores, celulares, jogos eletrônicos etc.) não contribui para a compreensão das transformações da infância e para a historicização desse fenômeno. ${ }^{13}$ Com o conjunto dos dados é possível, no mínimo, especular acerca das crianças e de seus brinquedos e brincadeiras.

As crianças que produziram os textos que ficaram registrados nos cadernos relatam brincadeiras e o uso de tradicionais brinquedos, tanto em atividades feitas em casa, quanto em passeios nas casas de amigos e familiares e nas curtas viagens realizadas. Indaga-se, portanto, do que e como brincavam essas crianças? Das recorrências localizadas no estudo, é possível dizer que entre as brincadeiras coletivas estão: "brincar de colégio", de boneca, de carrinho, de panelinha, andar de patins, de bicicleta, jogar videogame, jogar bola; além de atividades como ver DVD e TV, além de ajudar os pais em pequenas tarefas domésticas e, por vezes, estudar (ou dizer que estudaram!). No texto mais antigo localizado no estudo, no caderno do ano de 1957, por exemplo, é descrito o que segue:

\section{E gostei muito das ferias eu brincava Nas ferias estudei muito nas ferias. Passei muito nas férias \\ Estudei muito nas ferias \\ Eu trabalhei muito na férias. (C1, 1957, 2a série, F, EPu, Morro Redondo, RS [Santo Amor])}

Brincar, estudar e trabalhar, eis as atividades que a aluna afirma ter feito durante suas férias. É importante frisar que Santo Amor, indicado no caderno como o local da escola, é uma zona colonial do município de Morro Redondo, na Região Sul do Rio Grande do Sul. Trata-se, portanto, de uma escola da zona rural e de uma criança moradora do campo. Possivelmente, para além de tentar agradar a professora com a tradicional redação das fé-

13 Não há e não pode haver, nesses casos, uma visão ingênua e a-histórica da problemática das tecnologias na vida das famílias e das crianças. 0 que se pretende com essas afirmativas é tão somente chamar a atenção para um discurso genérico e, por vezes, descontextualizado, e não minimizar essa realidade. 
rias, afirmando que durante esse período ela também estudou muito, parece que trabalhar e brincar faziam parte do cotidiano dessa menina e quiçá de muitas outras crianças que viveram em tais condições, nos anos de 1950 e subsequentes, até os dias atuais.

No que tange aos debates sobre infância e história da infância, tal dado é bastante relevante. Os estudos nesses campos, desde o clássico de Philippe Ariès (1978 [1973]), têm mostrado que a infância é um constructo social, histórico e cultural, variável no tempo e no espaço. As crianças não são as mesmas, independente de quando e de onde nascem e vivem, mas variam significativamente e suas experiências são singulares, conforme a época, o lugar de suas existências, o pertencimento social, étnico-racial e de gênero. 0 dado possivel de ser extraído e problematizado em textos como o anteriormente reproduzido, ou, no mínimo, a indagação possível é: teriam as crianças que vivem no campo experiências gerais e, especificamente, de férias, de atividades culturais, de brinquedos e brincadeiras, muito diferentes das crianças que vivem em zonas urbanas, especialmente daquelas dos grandes centros? Os dados de que se dispõe são insuficientes para uma resposta absoluta, mas podem ser problematizados no conjunto de outros estudos que mostram que contextos diferentes (familiares, sociais, geográficos, históricos, étnicos, de gênero) influenciam modos diversos de trabalhar, de estudar e de brincar entre as crianças e os adolescentes (FRIEDMANN, 2012; KOTHE; KIRCHNER, 2015).

Ainda sobre brincar, estudar e visitar parentes nas férias, um outro exemplo, de um caderno de 1996, é reproduzido a seguir. Igualmente, nesse caso, o enunciado da professora foi copiado no caderno e diz: "Escreva 5 coisas que você fez nas férias". A menina (assim como Guilherme Pontes Pereira e Santiago) cumpriu a tarefa nos seguintes termos:
Brinquei com meus primos

Fui dormir na minha tia

Andei de roler

Fui lá na minha avó

Estudei a tabuada. (CO1, 1996, 2a série, F, EPu, Três Passos, RS)

Se, de fato, a menina que registrou esse texto estudou ou não a tabuada, não está em questão, pois não se pretende verificar a veracidade do que dizem as crianças, alunos e alunas dos anos iniciais da escola. Textos como o desse exemplo anteriormente reproduzido são os mais comuns e indicam, pelo menos, alguns aspectos que merecem atenção: o primeiro, já salientado, são as brincadeiras e os brinquedos que as crianças têm tido acesso e mantido, no caso, para o período em evidência: a partir dos anos de 1950, com ênfase para os anos de 1990 em diante, em razão das fontes de pesquisa que são em maior número para esse período; o segundo, a referência ao trabalho, pequenas tarefas domésticas e colaboração com os pais, e o registro, no esteio da cultura escolar e docente, que as férias tiveram, também, momentos de estudo; por fim, aquilo que é mais evidente, no conjunto dos textos coletados e já referido, a rede de relações familiares das crianças: avós e avôs, tios e tias, padrinhos e madrinhas, primos e primas, aparecem de forma recorrente nos textos, indicando relações familiares expandidas e importantes na vida das crianças, seja daquelas que vivem na cidade ou no campo. Nesse caso, sem generalizar afirmativas, pode-se dizer que as crianças revelam conviver com diferentes membros familiares, de diferentes gerações (de avós aos primos pequenos, por exemplo) e que o contato com eles durante os períodos de férias escolares são vivências importantes, ou, pelo menos, elas dizem que são, o que por si só já é significativo.

A relação com os familiares, nesse caso com a avó, aparece igualmente no texto a se- 
guir, além de atividades próprias da vida no campo, como buscar ovos no galpão e apanhar pêssegos na lavoura. Intitulado "Como foi o meu domingo", uma menina de uma escola pública do município de Canguçu assim escreveu:

Hoje eu acordei de manhã e fui brincar na minha vó eu brinquei de esconder com minha vó e eu também tirei ovo dos ninhos do galpão e comi salada de frutas e comi arroz de leite depois eu fui na lavora apanhar pessego e depois mais tarde eu fui dormir. (C63, 2010, N/C, F, EPu, Canguçu, RS)

Registre-se que a escola em que esse caderno foi usado localiza-se no município de Canguçu, na Região Sul do Rio Grande do Sul, considerado o município com maior número de minifúndios da América Latina. ${ }^{14}$ Assim, a experiência relatada tem a ver, obviamente, com o contexto de sua inserção. Essas crianças se não são filhas de pequenos agricultores, são netas de famílias com essa configuração. Os textos refletem, de alguma forma, essa realidade e essas vivências. Para além disso, permitem pensar os tempos da infância, as relações estabelecidas com e pelas crianças (a avó brinca de esconder com a neta?), as transformações no cotidiano das famílias etc.

A pesquisadora alemã Helga Zeiher (2007) analisa o tempo da profissão e o tempo da família, em relação às mudanças sociais, especialmente em sociedades altamente industrializadas, mostrando como o cuidado com as crianças tem se modificado, indicando um processo de desprivatização e desfamiliarização da infância. Contudo, no confronto com os indícios dos textos das crianças aqui referidos é possivel dizer que, em diferentes contextos

14 "Canguçu é um dos poucos municípios com mais de 50 mil habitantes a manter a população rural maior do que a urbana. O título de Minifúndio das Américas se deve ao grande número de propriedades rurais: 17,3 mil, segundo dados do Instituto Nacional de Colonização e Reforma Agrária (INCRA). Dos 53 mil habitantes, $63 \%$ ainda residem nos cinco distritos do interior". Disponivel em: <http://www.cangucu.rs.gov. br/site/noticia>. Acesso em: 18 fev. 2017. sociais, culturais, geográficos, étnicos, religiosos, outras práticas e outras relações estão sendo construídas, especialmente por esses sujeitos que "constroem história e criam cultura" (PRADO, 2005 p. 107), que são as crianças, na relação com seu grupo familiar ampliado.

Da mesma menina e no mesmo caderno, chama a atenção, também, um outro texto de sua autoria. Igualmente intitulado "Meu domingo" - talvez uma prática da professora para estimular a produção textual das crianças -, a aluna escreveu:

Eu acordei e eu e o meu pai asistimos o picapal. Depois que eu e o meu pai asistimos o picapal agente foi na pracinha e eu andei de bicicleta e de balanço e de escorregador. depois eu e o meu pai brincamos de escondi escondi e depois eu e o meu pai agente foi no Alemão e agente comeu pizza tomamos um Refri e depois a gente voltamos para casa. (C63, 2010, N/C, F, EPu, Canguçu, RS)

Muitas atividades - reais ou imaginárias foram descritas pela criança, um intenso dia somente com o pai teria sido vivido: desde cedo, com a programação vista conjuntamente na televisão, seguida de brincadeiras ao ar livre - bicicleta, pracinha e esconde-esconde -, prosseguida de uma visita ao "Alemão",15 passeio regado a refrigerante e pizza, com, enfim, o retorno para casa. Teria sido, assim, um domingo alegre de brincadeiras e passeio com o pai. o texto sugere uma sintonia, uma identificação, uma afinidade entre pai e filha, que não é possivel de averiguar, nem é o propósito. 0 importante, nesse caso, é perceber que a escrita da criança indica para uma construção de sentidos: se de fato seu domingo não foi assim, ela gostaria que tivesse sido!

Ainda em relação aos brinquedos e às brincadeiras, um texto intitulado "As Férias da Turma", de um 2o ano, do ano de 2010, é interessante, pois registra o que segue:

15 Uma conhecida e tradicional lanchonete da cidade. 
As Férias da Turma

A turma do 20 ano teve duas semanas de férias em julho

Cada aluno fez coisas diferentes e com certeza divertidas

Agora cada um vai contar um pouquinho do que fez

Ana Paula: Brincou de comidinha, brincou de barro.

Marco: Foi para a casa do pai, comeu muito bombom e jogou play 3

Aislam: Ajudou o pai a encerra o gado e brincou Lara: Deu comida para as galinhas, jogou no computador

Jariel: Andou a cavalo fez um carrinho boiadeiro David: Andou de bicicleta e brincou de carrinho da hotl

Yuri: Jogou vídeo game brincou de carrinho Laertty: Foi para fora ver os caras correr Diulia: Na dinda brincou com a Mila

Tais: Foi na dinda, brincou de casinha, jogou bola

Cassiano: Jogou vídeo game e andou de carrocinha

Natanieli: Andou de bicicleta e foi na casa da tia Patricia: Jogou bola e volei brincou de casinha, olhou DVD. (C48, 2010, 2o ano, F, EPu, Capão do Leão, RS)

Muitas e variadas atividades e brincadeiras são reveladas nesse texto coletivo, de um 20 ano (possivelmente, então, crianças entre 7 e 8 anos), de uma escola pública: brincar de comidinha, de barro, de casinha, de carrinho, jogar videogame ou computador, jogar bola, andar de bicicleta, de cavalo e de carrocinha etc. ${ }^{16}$ Mesmo considerando essa variação, um olhar atento revela que há, nas brincadeiras e atividades registradas, certa divisão de gênero: Ana Paula, Tais e Patrícia dizem ter brincado de casinha, mesmo que a primeira tenha "brincado de barro" e as duas últimas “jogado bola"; por sua vez, Jariel, David e Yuri afirmaram ter "brincado de carrinho", brinquedo e brincadeira histórica e culturalmente reservada aos meninos.

16 A colaboração nas tarefas dos pais, reaparece aqui, em pelo menos dois casos: Aislam: ajudou o pai a encerrar o gado; Lara: deu comida para as galinhas. E ambos remetem a atividades com características rurais.
Mas no que se refere a gênero, o texto " 0 que fiz nas minhas férias", escrito no caderno de uma menina que frequentou a 3a série, em 1994, em uma escola particular é o mais revelador de uma dada realidade de gênero:

Era uma vez eu e Alexandra estavamos brincando de colégio e a minha mãe chegou e agente estava mechando nas coisa da lojinha que a mãe tinha.

Aí eu fui na Paula e a gente andou de patins e eu cai de joelho e o Willian rio, rio que eu tinha caído.

Depois eu e a Paula fomos brincar de Barbie e o William queria brincar de Barbie e a mãe de Paula chamou ele de menininha brincando com Willian e ele potou para chorar e a mãe da Paula foi ao supermercado e a gente ficou andando de patins na rua e o Pig ficava pulando na gente e a Paula passou de patins en cima do pano dele e ele ficou brabo.

Ai a mãe da Paula chegou e a Paula pediu para fazer um bolo e ela deixou e a gente fez uma sujeira e a gente colocou no micro-ondas e levou 8 minutos.

Aí a minha mãe chegou e eu levei um pedaço de bolo para a minha casa.

Só fiz isso nas férias. (C22, 1994, 3a série, F, EPa, Rio Grande, RS)

Willian, chamado de menininha porque queria brincar de Barbie, foi interditado e humilhado, por querer participar da brincadeira de bonecas, "coisa de menina". Assim, o registro da aluna de uma 3a série permite refletir o quanto as brincadeiras ainda "têm gênero" e, com isso, ajudam a reforçar os estereótipos sociais de homem e de mulher. Além disso, é preciso compreender que as brincadeiras estão “inseridas num sistema social, [são] possuidoras de funções sociais, produtos e produtoras de uma sociedade dotada de traços culturais específicos (PRADO, 2005, p. 98-99). Nesse caso, na sociedade contemporânea brasileira, menino ainda não pode brincar livremente de boneca! Há, portanto, um longo caminho a ser percorrido, no que tange aos preconceitos e à equidade de gênero. 
Para encerrar essa seção, vale retomar seu objetivo, qual foi: problematizar os textos das crianças no que se refere a passeios e viagens familiares. Se foi possivel ampliar e destacar outros aspectos, que não restritos a isso, é justamente porque, ao escrever suas experiências de passeios e viagens, como tarefa escolar, as crianças, mesmo que com poucas habilidades linguísticas e textuais, expressam relações e fatos sociais e culturais, revelam desejos e intencionalidades, indicam ações e reações na e da vida cotidiana. Esse também foi, portanto, um esforço de "ouvi-las" e "vê-las", tentando capturar, por vezes no detalhe, no vestígio, suas ações, vivências e experiências cotidianas.

Segundo Lopes e Galvão (2001, p. 64), “uma das principais dificuldades para se fazer a história da infância é exatamente a ausência de registros que tenham sido produzidos pelas próprias crianças: afinal, elas não deixam testemunhos escritos, pessoais ou coletivos". Contudo, é possivel relativizar a afirmativa das autoras. Mesmo que se reconheça a dificuldade em localizar produções infantis, os registros encontrados nos cadernos pesquisados, especialmente os textos em que as crianças escrevem algo sobre si, seus familiares e suas vidas, permitem afirmar que há rarefação desses dados, mas não sua completa ausência. Trata-se de um esforço que pesquisadores e pesquisadoras precisam fazer para seguir os rastros que as crianças deixam, seja em registros escolares ou não-escolares, sejam escritos, desenhados ou gravados.

Na sequência, procurar-se-á problematizar os passeios e as viagens escolares, a partir dos textos das crianças presentes nos cadernos.

\section{Viagens e passeios escolares nos cadernos dos alunos}

Em relação aos passeios e viagens escolares, o esforço é compreender que tipo de expe- riências dessa natureza as crianças têm tido no âmbito escolar, bem como evidenciar o quê esses registros revelam da escola como instituição cultural e das propostas pedagógicas, no período em questão.

As viagens e os passeios escolares, de cunho cultural e pedagógico, estão registrados e referem-se a visitas a locais públicos, como redação de jornais, emissoras de rádio, bibliotecas, feiras do livro, cinema, museus etc., como se pode ver nos exemplos a seguir:

\section{Nosso passeio}

Já que 5 de maio foi o dia das comunicações programamos um passeio até o jornal, Alto Jacuí e á Biblioteca municipal. Lá no jornal, nos vimos como se faz um jornal. Achamos muito interessante. Saindo do jornal, fomos até a biblioteca e achamos os livrinhos muito bacanas. Tivemos oportunidade de ler Educação, pela sala da profe Nerziz.

Gostamos muito do nosso passeio, apenas cansamos um pouco. (CO1, 1990, 3a série, F, EPa, Ibirubá, RS)

HOJE À TARDE ESTAVA ENSOLARADA ENTÃO RESOLVEMOS FAZER UMA VISITA À BIBLIOTECA DO SESI. CHEGAMOS LÁ VIMOS MUITOS LIVROS, UM TAPETE COM ALFABETO DE ANIMAIS. DEPOIS FOMOS PARA O ESPAÇO ONDE SÃO APRESENTADOS OS TEATROS, PASSAMOS PARA O LABORATÓRIO E VIMOS UM ESQUELETO.

ASSISTIMOS UM FILME QUE FALAVA SOBRE O MEIO AMBIENTE, BRINCAMOS NA PRACINHA. ${ }^{77}$ (C31, 2007, 1ạ série, M, EPa, Bagé, RS)

Embora seja incomum, por vezes, na escola também se "passeia para brincar", como no caso reproduzido na sequência:

Ontem dia 22 de março quinta-feira fui na praça Carlos Gomes com os colegas da 1ạ A. Lá nos brincamos no helicóptero, barco, escorregador, gangorra, foguete, dinossauro, túnel, balança, cavalo...foi muito legal.18 (C31, 2007, 10 ano, M,

17 Texto assim reproduzido para marcar o tipo de letra usado nesses casos, a maiúscula, também chamada de bastão ou de caixa alta.

18 Observe-se que esse texto, como os demais referentes aos passeios escolares, tem uma correção linguística que deve ter passado pelo crivo da professora. $\mathrm{E}$ 
EPa, Bagé, RS)

Por vezes, também, pode-se perceber que os passeios têm um caráter mais lúdico, especialmente no caso dos primeiros anos escolares. Dois exemplos são mostrados, ambos de classes de 10 ano:

\section{O circo}

Hoje nós fomos ao circo.

Nos adoramos os palhaços.

O circo estava legal! (C11, 2000, 1ạ série, M, EPu, Pelotas, RS)

HOJE NÓS VAMOS NO CINEMA VER O FILME DO TIGRÃO.

NÓS VIMOS O FILME ESTAVA MUITO BOM O TIGRÃO DESCOBRIU QUE SEUS AMIGOS ERAM COMO SUA FAMÍLIA. (C11, 2000, 1ㅇ ano, M, EPu, Pelotas, RS)

Contudo, os passeios didático-pedagógicos, especialmente aqueles planejados para ensinar algum conteúdo específico do currículo escolar são os mais recorrentes. As temáticas dos vegetais, dos bichos, do meio ambiente e do sistema monetário aparecem nos textos a seguir exemplificados:

O Passeio

Hoje nós fomos dar um passeio

Olhar os vegetais.

A professora foi junto

A gente é muito distraído

Porque a gente passa pelos vegetais todos os dias mas nem olha. (C03, 1988, 2a série, F, EPu, Morro Redondo, RS)

Nós da 1a série da sala 70 e as professoras fomos passear.

Fomos a procura de bichinhos, plantas, areia, terra e pedra para montar um terrário.

Achamos primeiro a areia depois a terra, plantas, pedras e os bichinhos.

Voltamos para a escola nosso terrário estava pronto e muito bonito. (C03, 2002, 1a série, F, EPu, Santa Rosa, RS)

possivelmente, diferente dos anteriores, dos passeios e viagens familiares, trata-se de textos produzidos e corrigidos coletivamente pela turma. Eis a razão provável dos poucos erros ortográficos, de pontuação e de estrutura textual.
ONTEM FIZEMOS UM PASSEIO PELO QUARTEIRÃO PARA OBSERVARMOS O MEIO AMBIENTE. VIMOS LIXO PELO CHÃO, CASAS, CARROS, PRÉDIOS, ÁRVORES, ESGOTO ESCORRENDO, PAREDES RISCADAS.

FICAMOS TRISTE COM O QUE VIMOS. (C31, 2007, 1a série, $M, E P a$, Bagé, RS)

\section{Redação}

Passei ao supermercado

Nossa turma foi ao supermercado apos aprender o sistema monetario

La no supermercado compramos nosso lanche com muinta atenção na hora de coferir o troco Nosso paseio foi muinto divertido. (C35, 2011, 20 ano, $\mathrm{M}, \mathrm{EPa}$, Pelotas, RS)

Nessa mesma perspectiva, há registro de uma visita de estudos em um caderno de um aluno brasileiro que estudou em Lisboa, Portugal, em 1999. Nesse caso, a visita foi ao Museu da Cidade e o conteúdo era os descobrimentos portugueses:

No dia 2 de Março fomos fazer uma visita de estudos no Museu da Cidade. Pegamos o autocarro no 78 e fomos até lá.

Fomos direto a uma sala que tinha algumas coisas sobre a época dos descobrimentos portugueses. Ouvimos uma palestra feita pela $\mathrm{Ca}$ tarina (a nossa guia) e fizemos tipo um teatro que foi assim: as meninas foram para um lado e os meninos para outro. Cada um escolhia um nome da época. Seis rapazes foram escolhidos para representar os marinheiros que vinham da Índia um outro menino representou o escrivão da Casa da Îndia. A Catarina entregou um pote de especiarias para cada um; cada pote continha uma especiaria, elas eram: canela, açafrão, caril, cravinho, pimenta e noz Moscada. Esses meninos tinham que declarar ao escrivão seu nome inventado e a sua especiaria.

As meninas e os outros meninos iriam para a Índia. E a representação foi assim: as meninas tinham que dar o nome inventado para viajar e os meninos além de inventar o nome tinham que inventar uma profissão que era realizada em barcos e tinha que dar isso também para o escrivão.

Depois fomos ver o mapa das rotas marítimas. Imaginamos que íamos para a Índia. Então, se 
íamos para a Índia tínhamos que rezar; daí fomos na maquete do Mosteiro dos Jerônimos, logo depois fomos para a maquete da Torre de Belém para partir para a Índia.

Vimos a maquete da cidade, alguns azulejos e fomos embora. (CO8, 1999, 4a série, M, EPu, Lisboa, PT)

Um passeio com muitas atividades e provavelmente com a intencionalidade da professora de reforçar o conteúdo estudado em sala de aula ou de apresentá-lo aos alunos para posterior desenvolvimento na escola. 0 que é possivel perceber, contudo, é que havia um propósito definido para tal passeio.

Igualmente, no mesmo caderno, há avisos de muitos outros passeios, como o que segue, indicando a incidência dessas atividades naquele contexto: ${ }^{19}$

Aviso:

Informo V. Exą- que na próxima segunda feira dia 26 de Abril iremos aos "Palácio da Independência".

A saída está para as 9 h30 e a chegada para as 12:30.

Mais informo que cada aluno terá de pagar $640 \$ 00 / 250 \$ 00$ entrada e $490 \$ 00$ camioneta Lisboa, 26/4/99. (CO8, 1999, 4a série, M, EPu, Lisboa, PT)

Na sequência, no caderno, está o texto que relata a visita, assim descrita:

Visita ao palácio da Independência

1o nós fomos a uma explicação sobre Cuchim, depois uma explicação sobre Goa que foi conquistada por Afonso de Albuquerque em 25/1510 dia de S. Catarina. Depois fomos para uma sala que representava uma nau e logo após uma de uma igreja. Andamos um pouco e fomos a "Sala do Baú" que tem o "guarda-roupa" Indiano e o mercado e fingimos ser vendedores e compradores. Depois jogamos computadores. (CO8, 1999, 4a série, M, EPu, Lisboa, PT)

19 O Movimento da Escola Moderna, cujo mentor foi Célestin Freinet, e que preconizava as aulas-passeio e as viagens de estudos tem, até hoje, em Portugal, muitos seguidores e adeptos. Adiante, tal movimento será referido.
Assim como no passeio ao Museu da Cidade, a visita ao Palácio da Independência, em Lisboa, tinha provavelmente a intencionalidade de desenvolver o conteúdo referente às conquistas portuguesas com a turma de 4 a série. Como se sabe, Cochim e Goa, cidades da Índia, estiveram sob o domínio de Portugal e ambas foram capitais da Índia portuguesa no século XVI. Tratou-se, assim, de um "passeioconteúdo" ou, na expressão de Sampaio (1994), um "passeio-informação".

De outro caderno, de uma menina de um 4을 ano, de uma escola particular de Pelotas, do ano de 2013, vem o último exemplo de uma viagem de estudos. Ela foi feita à cidade de Piratini, no Rio Grande do Sul, e o texto é exemplar de um registro de viagem de caráter didático pedagógico, com conteúdos e informações apreendidas:

\section{VIAGEM À PIRATINI!!!}

Othello Moreira Fabião foi um homem muito importante. Ele ajudou á fundar Piratini. Ele tem dois títulos de eleitor.

A CASA verde

Inacia Machado Silveira foi a 1a professora de Piratini. Ela viveu na casa verde (agora pintada de azul).

CASA do General Neto

Genereal Neto morou aqui. Ele foi importante. Ele proclamou a república Rio grandense.

Gomes de Freitas

Ele "fugiu" da revolução Farroupilha. Quando ela acabou, ele voltou. Ele foi um juiz de paz. CASA DA Camarinha

Ela pertenceu aos açorianos. Por que casa $\mathrm{Ca}-$ merinha? Por quê ela tem uma espécie de camarim onde aconteciam reuniões, etc.

Tiatro 7 de Abril

Era pequeno, existio por pouco tempo. Ele foi construído mais ou menos no ano de 1878.

Significado de Piratini: Peixe Barulhento (Tupi guarani). (C19, 2013, 4음 ano, F, EPa, Pelotas, RS)

Os passeios escolares, viagens de estudos e/ou excursões, cujos exemplos estão reproduzidos anteriormente, não são recentes na história da escola mundial e brasileira. Quan- 
do tal temática está em evidência é preciso, pelo menos, voltar ao século XIX e compreender a expansão dessas atividades no bojo de um dos mais importantes movimentos educacionais de todos os tempos: o movimento da Escola Nova.

Em outro estudo (PERES, 2005), mostramos que esse foi um movimento que tomou forma em praticamente todo o mundo, no final do século XIX e início do século XX, e que pretendia, entre outras coisas, estabelecer uma nova ordem social via escola, reformar a sociedade pela educação, em outras palavras, renovar a escola para renovar a sociedade. Em razão disso, temas como educação e democracia; escola para todos; educação e vida; caráter científico da educação; formação das elites; aptidões e capacidades individuais; formação integral; interesse e necessidades das crianças; desenvolvimento infantil; liberdade, individualidade, espontaneidade e autonomia dos educandos; autogoverno; valorização da experiência; educação moral, intelectual e física; métodos ativos de ensino, entre tantos outros, tiveram centralidade nas discussões e nas produções dos pensadores ligados à Escola Nova.

O tema dos métodos pedagógicos também esteve em pauta nesse movimento. Tratava-se de defender uma escola mais dinâmica, mais ativa, mais interessante para as crianças. No bojo desse debate, estava a defesa dos passeios, excursões, viagens de estudos, dos quais a escola atual é herdeira.

Numa reunião realizada em Calais, na França, em 1919, foram assentados os chamados trinta pontos da Escola Nova, ${ }^{20}$ que sintetizavam as características gerais das "escolas novas no campo", ou seja, da Escola Nova em seu sentido original. ${ }^{21}$

20 Os trinta pontos ou características da Escola Nova foram publicados no Brasil, em Introdução ao Estudo da Escola Nova, de Lourenço Filho (1978).

210 ponto de número 3, quanto à organização geral, refere: "A Escola Nova está situada no campo, porque este constitui o meio natural da criança. 0 influxo
Como foi referido no estudo supracitado (PERES, 2005), segundo Adolphe Ferrière (1915, p. 9), um dos arautos da Educação Nova, os trinta pontos foram resultado do registro das experiências e dos contatos de mais de quinze anos com “Escolas Novas autênticas". Em razão disso, entre as características dessa proposta estava a previsão de seu funcionamento em forma de internato no campo, origem das primeiras experiências do que se convencionou chamar Escola Nova na Europa (França, Alemanha, Inglaterra e Bélgica). Os trinta pontos contemplam ainda questões que seriam verdadeiras "bandeiras de luta" dos escolanovistas de várias partes do mundo, inclusive do Brasil, a exemplo da coeducação dos sexos, dos trabalhos manuais na escola, da educação integral (educação moral, física e intelectual), dos trabalhos livres, do trabalho coletivo, da (re)organização do tempo escolar, das excursões pedagógicas, da auto-organização dos alunos (sistema de república escolar), do ensino baseado na experiência e nos fatos, na atividade pessoal e nos interesses espontâneos dos alunos etc.

Em relação às excursões escolares, no ponto 10, do item QUANTO À ORGANIZAÇÃO GERAL, lê-se:

As excursões, a pé ou em bicicleta, com acampamentos em tendas de campanha e refeições preparadas pelos próprios alunos, desempenham um papel importante na Escola Nova. Tais excursões, adrede preparadas, coadjuvam o ensino.

Ainda no item denominado QUANTO À FORMAÇÃO INTELECTUAL, no ponto de número 13, lê-se:

O ensino será baseado sobre os fatos e a experiência. A aquisição dos conhecimentos resulta de observações pessoais, visitas a fábricas,

da natureza, as possibilidades que oferece para empreendimentos simples, os trabalhos rurais que permite realizar, representam o melhor auxílio à cultura fisica e moral. Para progresso intelectual e artístico, é desejável, porém, que fique próximo a uma cidade". (LOURENÇO FILHO, 1978) 
prática de trabalho manual, etc., e, só em falta, da observação de outros, recolhida através dos livros. A teoria vem sempre depois da prática, nunca a precede. (LOURENÇO FILHO, 1978)

Vários pensadores da Escola Nova, entre eles Édouard Claparède (1873-1940), Adolphe Ferrière (1879-1960) e Pierre Bouvet (18781965), iriam defender de forma veemente, ao longo da vida, o ensino ativo e, nesse contexto, a importância e o caráter didático-pedagógico das observações, visitas, excursões e viagens de estudos, porque "coadjuvavam o ensino" e permitiam que a prática precedesse a teoria, na esteira daquilo que acreditavam e advogavam. Mas quem de fato contribui significativamente na divulgação da chamada técnica da "aula-passeio" foi o professor francês Célestin Freinet (1896-1966). Toda formulação pedagógica de Freinet, que aliava teoria e prática, ficou conhecida como movimento da Escola Moderna. ${ }^{22} \mathrm{Em}$ relação aos passeios escolares, em uma de suas obras descreve como fazia isso:

A aula-passeio constituía para mim uma tábua de salvação. Em vez de me postar, sonolento, diante de um quadro de leitura, no começo da aula da tarde, partia com as crianças pelos campos que circundavam a aldeia ${ }^{23}$. Ao atravessarmos as ruas, parávamos para admirar o ferreiro, o marceneiro ou o tecelão [...]. Observávamos o campo nas diversas estações: no Inverno víamos os grandes lençóis estendidos sob as oliveiras para receber as azeitonas varejadas; na Primavera, as flores de laranjeira em todo o seu encanto [...]; já não examinávamos, como

22 Célestin Freinet afirmou: “Já dissemos num estudo anterior: não há método Freinet. [...] Somos, já dissemos, um movimento pedagógico, um amplo movimento que visa adaptar, na prática, as nossas escolas às necessidades do momento actual e aos meios que hoje em hoje em dia a organização social e científica põe à disposição. Antes do mais, somos práticos e trabalhamos sem ideias preconcebidas contra determinada técnica ou método". (FREINET, Élise, 1978 [1969])

23 Célestin Freinet começou sua carreira docente como professor primário, na localidade de Bar-sur-Loup, França, e, posteriormente, lecionou em Saint-Paul. Para saber mais sobre a vida e obra de Freinet ver: Freinet, Élise (1978 [1969]). professor e alunos, em torno de nós, a flor ou o insecto, a pedra ou o regato. Sentíamo-los com todo nosso ser, não só objectivamente, mas com toda nossa sensibilidade natural. E trazíamos as nossas riquezas: fósseis, nozes, avelãs, argila ou uma ave morta. (FREINET, 1976 [1964], p. 23)

Não cabe nos limites desse artigo, não é seu propósito, aprofundar as ideias freinetianas; contudo, é preciso observar que os passeios e as viagens de estudos localizados nos cadernos dos alunos e alunas seguem uma tradição pedagógica de longa data que precisa ser referida e compreendida nos seus princípios teóricos, mesmo que professores e professoras tenham perdido essa referência histórica e continuem fazendo tais atividades em razão de uma prática instituída na e pela referida tradição didático-pedagógica.

\section{Considerações finais}

A primeira pergunta que se pode colocar na finalização desse estudo é a seguinte: sob qual perspectiva as crianças, alunos e alunas da fase inicial da escolarização, registram suas experiências familiares de viagens e passeios? O segundo questionamento é: o que os textos das crianças permitem apreender sobre viagens e passeios no espaço escolar?

Assim, pretende-se que essas duas indagações sejam respondidas nos limites que os dados permitem - portanto, da própria fonte de investigação, os cadernos escolares. Além disso, espera-se que o estudo possa suscitar outros, especialmente no que tange aos registros escritos das crianças, tão dificeis de serem problematizados dos pontos de vista histórico, sociológico e antropológico, mas tão necessário.

Em relação ao primeiro questionamento, pode-se concluir que, no universo pesquisado, os textos das crianças indicaram aspectos como: os limites culturais e geográficos de seus 
passeios e viagens; a relação com familiares e amigos, aparentemente reforçadas em períodos de férias, em muitos casos em espaços rurais; a coexistência de um tempo de colaborar com os pais em pequenas tarefas domésticas, de estudar e de brincar, ainda, de algumas tradicionais brincadeiras infantis, com indicios de separação de gênero no que tange a essas brincadeiras e aos brinquedos.

Há, notadamente, uma diferença nos textos produzidos pelos alunos e alunas, quando escrevem sobre suas férias, passeios e viagens familiares e quando o fazem em referência a essas atividades realizadas no âmbito escolar. No primeiro caso, há uma escrita "mais livre", aparentemente menos controlada e menos corrigida, diferente daquela que registra passeios e viagens escolares.

Assim, em relação à segunda pergunta, pode-se enfatizar que poucos são os passeios ou viagens escolares registrados nos cadernos que revelam uma dimensão mais lúdica ou "passeio -repouso", como denominou Sampaio (1994, p. 81), em referência à aula-passeio da Pedagogia Freinet. O que os dados indicaram é a existência, na escola, de "passeios-informação" (SAMPAIO, 1994, p. 181), quais sejam, aqueles feitos espe-

\section{Referências}

ARIĖS, Philippe. História social da infância e da família. Tradução de Dora Flasksman. Rio de Janeiro: Guanabara Koogan, 1978 [1973].

BORGES, Francieli Daiane. Representações de leitores e leitoras na série Um Castelo no Pampa, de Luiz Antonio de Assis Brasil. 2015. 133 f. Dissertação (Mestrado em Educação) - Faculdade de Educação, Universidade Federal de Pelotas, Pelotas, 2015.

CECÍlIO, Maria Aparecida. A criança rural. Acta Scientiarum, Maringá, v. 24, n. 1, p. 167-173, 2002.

CHARTIER, Anne Marie. Um dispositivo sem autor: cadernos e fichários na escola primária. Revista Brasileira de História da Educação, Campinas, SP, cificamente para aprender ou reforçar um conteúdo escolar (vegetais, bichos, meio ambiente, sistema monetário, períodos e fatos históricos, como nos exemplos mostrados). Além disso, pelos textos, é possivel perceber que passeios e viagens escolares são feitos, na maioria das vezes, a lugares associados a uma "cultura legítima": museus, bibliotecas, cinema, casarões históricos. Nesse sentido, revelam também uma perspectiva de história, de memória e de cultura que a escola preserva e, inclusive, contribui para sua construção.

Para concluir, a palavra final fica para Roberto, aluno de uma turma de 2 o ano, em 2010, de uma escola pública, da cidade de Piratini. A professora solicitou: "Faz um verso com a palavra férias", e ele escreveu:

Feliz estamos comessando

é época de aproveitar

realizamos sonhos e viagens

i iremos passear e brincar

e amigos vin nos visitar

sejam felizes todos que férias irão tirar. (C36, 2010, 2o ano, M, EPu, Piratini, RS)

Roberto poetizou as férias, com felicidade, sonhos, viagens, passeios e brincadeiras! Teriam sido assim mesmo as suas férias?

Autores Associados, v 1. n. 3, p. 9-26, jan./jun. 2002.

Exercícios escritos e cadernos de alunos: reflexões sobre práticas de longa duração. In: CHARTIER, Anne Marie. Práticas de leitura e escrita. História e atualidade. Belo Horizonte: Autêntica; CEALE, 2007. (Coleção Linguagem e Educação). 2007. p. 21-66.

FERRIÈRE, Adolphe. Préface. In: FARIA DE VASCONCELOS A.. Une école nouvelle en Belgique. Préface de Adolphe Ferrière. Paris: Delachaux \& Niestlé, 1915. p. 7-20.

FRIEDMANN, Adriana. 0 brincar na educação infantil: observações, adequações e inclusão. São Paulo: 
Moderna, 2012.

FREINET, Célestin. As técnicas Freinet da escola moderna. 4. ed. Lisboa: Editorial Estampa, 1976 [1964].

FREINET, Élise. Nascimento de uma pedagogia popular. Os métodos Freinet. Lisboa: Editorial Estampa, 1978 [1969].

GRIBEL, Christiane. Minhas férias, pula uma linha, parágrafo. Ilustrações de Orlando. 4. reim. Rio de Janeiro, Salamandra, 1999.

GVIRTZ, Silvina. El discurso escolar através de los cuadernos de clase. Buenos Aires: Editorial Universitária de Buenos Aires, 1999.

HÉBRARD, Jean. Por uma bibliografia material das escritas ordinárias: o espaço gráfico do caderno escolar (França - séculos XIX e XX). Revista Brasileira de História da Educação, Campinas, SP, Editora Autores Associados, n. 1, p. 115-141, jan./jun. 2001.

KOTHE, Soeli; KIRCHNER, Elenice Ana. As peculiaridades da infância no contexto rural e urbano. In: SEMINÁRIO DE INICIAÇÃO CIENTÍFICA - SEMIC - Curso de Pedagogia da FAI, 6., 2015, Itapiranga. Anais... Itapiranga, SC: FAl, 2015. p. 1-9. Disponivel em: <http:// faifaculdades.edu.br/eventos/SEMIC/6SEMIC/arquivos/resumos/RES26.pdf>. Acesso em: $16 \mathrm{fev}$. 2017.

LOPES, Eliane Marta T.; GALVÃO, Ana Maria de O. História da educação. Rio de Janeiro: DP\&A, 2001.

LOURENÇO FILHO. Introdução ao estudo da Escola Nova. 13. ed. São Paulo: Melhoramentos, 1978.

MARCUSCHI, Luiz Antonio. Gêneros textuais: definição e funcionalidade. In: DIONISIO, Angela Paiva; MACHADO, Anna Rachel; BEZERRA, Maria Auxiliadora (Orgs.) Gêneros textuais e ensino. Rio de Janeiro: Lucerna, 2002. cap. 1, p. 19-36.

MIGNOT, Ana Chrystina Venancio. Cadernos à vista: escola, memória e cultura escrita. Rio de Janeiro: EdUERJ, 2008.

PERES, Eliane. A Escola Ativa na visão de Adolphe Ferrière - Elementos para compreender a Escola Nova no Brasil. In: STEPHANOU, Maria; BASTOS, Maria Helena C. (Orgs.). Histórias e memórias da edu- cação no Brasil. Petrópolis, RJ: Vozes, 2005. v. III, p. 114-128.

PERES, Eliane. Marcas da infância em cadernos escolares de crianças em processo de alfabetização. In: MIGNOT, Ana Chrystina Venancio. (Org.). Não me esqueça num canto qualquer. Rio de Janeiro: Laboratório Educação e Imagem, 2008. v. 1, p. 1-12.

PERES, Eliane. A produção sobre história da alfabetização no Rio Grande do Sul: as contribuições do grupo de pesquisa HISALES (FaE/UFPel). In: MORTATTI, Maria do Rosário Longo. (Org.). A alfabetização no Brasil: uma história da sua história. São Paulo: Cultura Acadêmica; Marília: Oficina Universitária, 2011. v. 1, p. 243-264.

PERES, Eliane. Um estudo da história da alfabetização através de cadernos escolares (1943-2010). Cadernos de História da Educação, UFU, v. 11, p. 93106, 2012.

PERES, Eliane; RAMIL, Chris de Azevedo. A constituição dos acervos do Grupo de Pesquisa História da Alfabetização, Leitura, Escrita e dos Livros Escolares e sua contribuição para as investigações em educação. Revista História da Educação, ASPHE/RS, v. 19, n. 47, p. 297-311, set./dez. 2015a.

PERES, Eliane; RAMIL, Chris de Azevedo. Cartilhas produzidas por autoras gaúchas: um estudo sobre a circulação e o uso em escolas do Rio Grande do Sul (1940-1980). Versão Impressa e Versão On-line. Revista Brasileira de Alfabetização/ABALF, Vitória, ES, v. 1, n. 1, p. 177-203, jan./jun. 2015b.

PRADO, Patrícia Dias. Quer brincar comigo? Pesquisa, brincadeira e educação infantil. In: FARIA, Ana Lúcia G. et. al. (Orgs.). Por uma cultura da infância. Metodologias de pesquisa com crianças. 2. ed. Campinas, SP: Autores Associados, 2005, p. 93-111..

REYES, Yolanda. Frida. Ilustrações de Olga Cuéller. Tradução de Ruth Rocha. 2. ed. São Paulo: FTD, 1999. (Coleção Histórias de Colégio).

SAMPAIO, Rosa Maria W. Freinet. Evolução histórica e atualidades. São Paulo: Editora Scipione, 1994.

SILVA, Carina. A questão da regularização fundiária no bairro Sanga Funda, Pelotas, RS. In: CONGRES- 
SO BRASILEIRO DE GEÓGRAFOS - A AGB e a Geografia brasileira com contexto das lutas sociais frente aos projetos hegemônicos, 7., 2014, Vitória. Anais eletrônicos... Vitória: AGB, 2014. p. 1-10. Disponivel em: <http://www.cbg2014.agb.org.br/resources/ anais/1/1404149912_ARQUIVO_COMPLETOCBG.pdf>. Acesso em: 24 jan. 2017.

VIÑAO, Antonio. Os cadernos escolares como fonte histórica: aspectos metodológicos e historiográficos. In: MIGNOT, Ana Chrystina Venancio. Cadernos à vista: escola, memória e cultura escrita. Rio de Janeiro: EDUERJ, 2008. p. 15-33.

ZEIHER, Helga. Tempo da profissão e tempo da família: suas modificações sociais. In: SOUZA, Gizele de. (Org.). A criança em perspectiva. Olhares do mundo sobre o tempo infância. São Paulo: Cortez Editora, 2007.

Recebido em: 09.03.2017

Aprovado em: 25.05.2017

Eliane Peres é Doutora em Educação pela UFMG. Realizou pós-doutorado na University of Illinois at Urbana-Champaign. É professora Titular da Faculdade de Educação, da Universidade Federal de Pelotas. Líder do grupo de pesquisa HISALES (História da Alfabetização, Leitura, Escrita e dos Livros Escolares).e-mail: eteperes@gmail.com

Faculdade de Educação, Universidade Federal de Pelotas - Rua Alberto Rosa, 154, Pelotas, RS

Telefone: (53) 3278-6908 